\title{
Intra-articular and circulating immune complexes and antiglobulins (IgG and IgM) in rheumatoid arthritis: correlation with clinical features
}

\author{
F. C. HAY, L. J. NINEHAM, R. PERUMAL, 1 AND I. M. ROITT
}

From the Department of Immunology, Middlesex Hospital Medical School, London, and the ${ }^{1}$ Department of Rheumatology, the London Hospital

SUMMARY Solid phase radioimmunometric methods have been used to assay immune complexes and IgG and IgM antiglobulins in paired samples of synovial fluid and serum from patients with rheumatoid arthritis (RA) or osteoarthrosis. Over $60 \%$ of RA patients had some increase in complexes in their sera, while nearly $90 \%$ had synovial fluid complexes. Moreover, the levels of complexes within the joint were much higher than in the serum. Both IgG and IgM antiglobulins were raised in most RA patients. The levels of IgG antiglobulins-and to a less extent IgM antiglobulins-were nearly always higher in synovial fluid than in the corresponding serum sample. A strong correlation was found between the levels of immune complex and IgG antiglobulin. A marked association was seen between the presence of subcutaneous nodules and increased IgG antiglobulins.

Antiglobulins (rheumatoid factors) present the most consistent serological feature in almost all patients with rheumatoid arthritis (RA). When both IgG and IgM antiglobulins are examined, even seronegative patients show higher than normal levels (Torrigiani, et al., 1970; Hay et al., 1975). Immune complexes are also often found in RA patients, particularly in the synovial fluid of inflamed joints. There is now good evidence that self-associated IgGantiglobulins constitute a significant part of these complexes (Kunkel et al., 1961; Winchester et al., 1970), and analysis has now shown that they also contain appreciable amounts of $\mathrm{Clq}$ and other complement components (Male, Roitt and Hay, unpublished). It seems likely, therefore, that these complexes are involved in mediating inflammatory tissue damage through activation of the complement system and the release of lysosomal enzymes from granulocytes and monocytes.

To look further at the relationship between immune complexes and antiglobulins we have used solid phase radioimmunometric assays to determine the amounts of immune complexes and IgG and IgM antiglobulins in paired samples of synovial fluid

Accepted for publication 21 March 1978

Correspondence to Dr F. C. Hay, Department of Immunology, Middlesex Hospital Medical School, Arthur Stanley House, 40-50 Tottenham Street, London W1P 9PG. and serum from patients with rheumatoid arthritis or osteoarthrosis. The degree of association between these parameters and the clinical status and treatment of these patients has been examined.

\section{Materials and methods}

\section{PATIENTS}

Synovial fluid samples were obtained from 15 RA patients who were positive to the sheep cell agglutination test (SCAT) and 2 who were SCAT-negative, together with paired serum samples from all but 1 of the patients. The patients satisfied the American Rheumatism Association criteria for classical (C), definite (D), or probable (P) RA. There were 14 women and 3 men aged 29 to 81 years, mean 56 years. The duration of disease was from 4 months to 27 years with a mean of 8 years. Disease activity was classified as very active (A), moderately active (M), slightly active (S), or inactive or quiescent (O). Definite erosions were recorded in 13 cases. Rheumatoid nodules were present in 6 , and 1 patient (No. 11) had Sjögren's syndrome in addition to nodules. None of the patients had detectable amyloidosis.

For comparison synovial fluid samples were obtained from 4 patients with osteoarthrosis (OA), with paired sera in 3 cases. These patients, 2 female 
and 2 male, were aged from 49 to 64 years, mean 57 years; with clinically detectable disease from 4 months to 21 years, mean 8 years. Normal control sera were also obtained from 8 ( 3 female, 5 male, aged 26 years to 49 years, mean 34 years) laboratory workers within the Immunology Department.

16 of the RA and all OA patients were regularly taking aspirin or other anti-inflammatory drugs, 7 RA patients were receiving systemic steroids, one azathioprine, one penicillamine, and 3 sodium aurothiomalate. One RA patient (No. 2) was not receiving any treatment.

\section{COLLECTION AND STORAGE OF SAMPLES}

The synovial fluids were collected from knee effusions into plain sterile bottles and stored at $-20^{\circ} \mathrm{C}$. Blood samples were collected into plain bottles immediately after the fluid aspiration and the serum stored at $-20^{\circ} \mathrm{C}$.

\section{HYALURONIDASE TREATMENT OF SYNOVIAL FLUID}

Aliquots of synovial fluid were mixed with hyaluronidase (Hyalase, Fisons), $75 \mathrm{IU}$ per $\mathrm{ml}$ synovial fluid, and incubated at $37^{\circ} \mathrm{C}$ for 30 minutes prior to testing (Hannestad, 1967).

\section{SHEEP CELL AGGLUTINATION TEST}

All serum samples were screened for classical rheumatoid factor with a sheep cell agglutination test kit (Rheumaton, Becton Dickinson).
ANTIGLOBULIN ASSAY

Aliquots of serum or hyaluronidase-treated synovial $\bar{\equiv}$ fluid were incubated at $56^{\circ} \mathrm{C}$ for 30 minutes toinactivate complement. Duplicate $50 \mu \mathrm{l}$ samples of $\frac{}{0}$ serum of synovial fluid were then tested in a solid $\overline{\bar{c}}$ phase immunoradiometric assay (Hay et al., 1975; Nineham, et al., 1976). The assay involved the binding of antiglobulins to rabbit immunoglobulin ${ }^{\circ}$ linked to the surface of plastic tubes; the amount $\vec{O}$ of antiglobulin bound was then determined by adding radiolabelled anti-human IgG or IgM.

The rabbit anti-human IgG employed as the radiolabelled reagent was prepared from a different pool of rabbit antisera from that used in previous $\infty$ studies. This new antiserum bound more avidly to- human IgG; therefore the apparent values for $\operatorname{IgG}_{0}$ antiglobulins are higher in the present series. The ranking of patients and normal controls remained the same, however.

IMMUNE COMPLEX ASSAY

Immune complexes were determined as described previously (Hay et al., 1976) with the following modifications. The assay involved the binding of the first component of complement C1q to plastic tubes. $1-\mathrm{ml}$ volumes of human C1q solution $10 \mathrm{mg} / \mathrm{l}$ in PBS were incubated in polystyrene tubes (LP3, Luck-ō ham Ltd., Sussex) for 3 days at $4^{\circ} \mathrm{C}$. After 3 washeso with PBS the tubes were filled with $0.01 \%$ gelatin 0 solution in PBS and incubated at room temperature for $2 \mathrm{~h}$. After 3 more washes with PBS the tubes were 3

Table 1 Immune complexes and antiglobulins

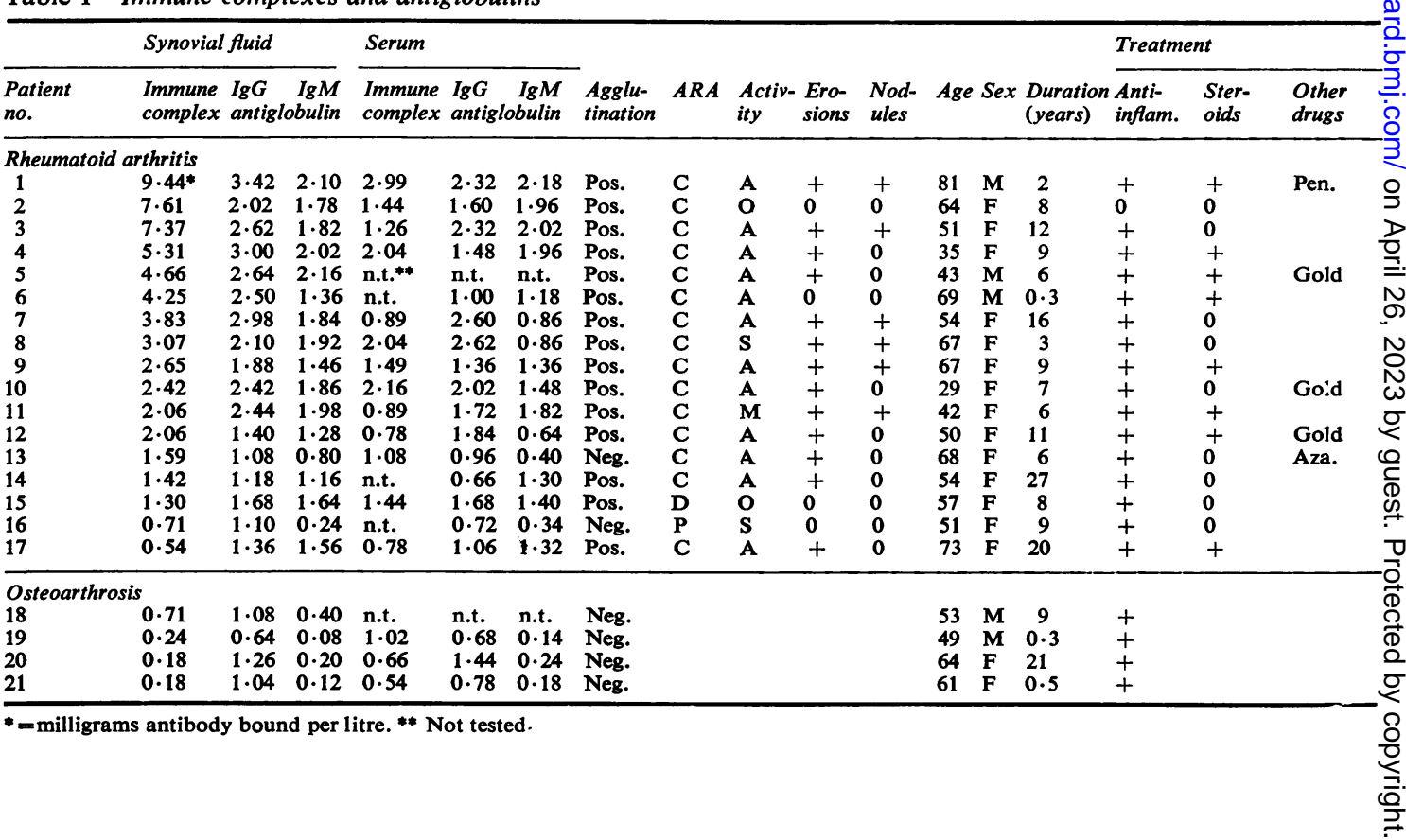


used in the immune complex assay. $50 \mu l$ of test serum or synovial fluid were mixed with $100 \mu \mathrm{l} \mathrm{Na} \mathrm{Na}_{2}$ ethylene diaminetetra-acetic acid (EDTA), $0.2 \mathrm{M}$ (adjusted to $\mathrm{pH} 7.5$ with $\mathrm{NaOH}$ ), and incubated for $30 \mathrm{~min}$ at $37^{\circ} \mathrm{C}$. The mixture was then transferred to an ice bath (Zubler et al., 1976). Duplicate 50 $\mu 1$ samples were placed in the coated plastic tubes together with $950 \mu \mathrm{l}$ of PBS containing $0.65 \%$ Tween 20 (PBS Tween).

Coated tubes containing $1 \mathrm{ml}$ PBS Tween were used as background controls. The tubes were incubated for $1 \mathrm{~h}$ at $37^{\circ} \mathrm{C}$ and for $30 \mathrm{~min}$ at $4^{\circ} \mathrm{C}$. Unbound proteins were then removed by washing 3 times with cold PBS. Immune complexes bound to the Clq-coated tubes were detected by incubating the tubes with $1 \mu \mathrm{g}$ of purified radiolabelled antiIgG in $1 \mathrm{ml}$ PBS Tween at $37^{\circ} \mathrm{C}$ for $1 \mathrm{~h}$ and at $4^{\circ} \mathrm{C}$ for $30 \mathrm{~min}$. Unbound labelled reagent was removed by 3 washes with cold PBS. The tubes were then counted in a gamma-ray spectrometer, the amount of radioactivity bound being a measure of the immune complexes in the patient's serum.

\section{Results}

The individual results for immune complexes and IgG and IgM antiglobulins for all samples of synovial fluid and patients' sera are documented in Table 1 . The mean values and percentage incidence of positive results in RA patients compared with OA synovial fluid or normal sera are summarised in Table 2.

\section{SYNOVIAL FLUID}

Immune complexes, IgG and IgM antiglobulins were all raised $(\mathrm{P}<0.01$; Student's $t$ test $)$ in the synovial fluids of RA patients when compared with OA (Figs. 1 and 2). Values for immune complexes were elevated in 15/17 RA patients, IgG antiglobulins in 14/17, and IgM antiglobulins in 16/17. The 2 seronegative patients had low levels of each factor. There was a strong correlation between the levels of immune complex and IgG antiglobulin $(r=0.75$, $P<0.001$; Fig. 3) and between the amounts of the 2 classes of antiglobulins $(r=0.79, P<0.001)$.

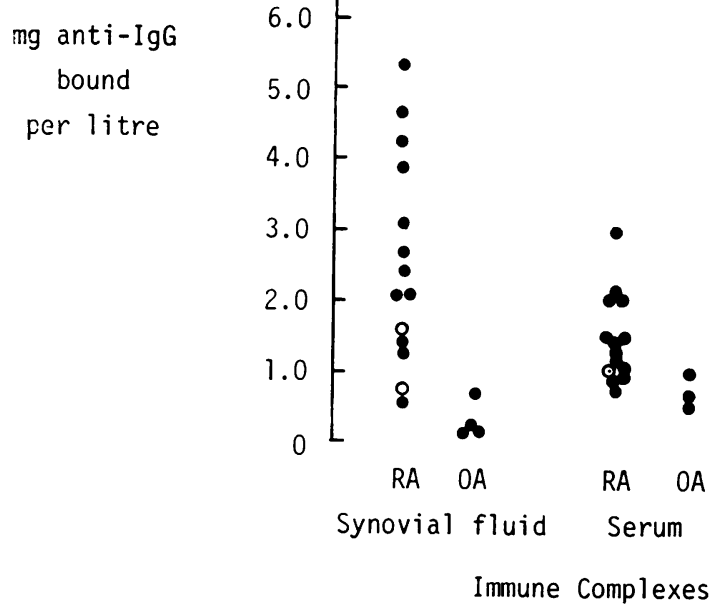

Fig. 1 Immune complexes in synovial fluid and serum in patients with $R A$ and $O A$. For the RA group open circles indicate SCAT-negative and closed circles indicate SCAT-positive patients. These symbols are used throughout all the Figures.

SER UM

Although immune complexes were raised in the RA group compared with OA sera and were above the normal range in $8 / 13$ patients (upper limit of normality defined as mean of normal controls +2 standard deviations $=1 \cdot 18 \mathrm{mg} / \mathrm{l})$, the increase was not significant $(P<0 \cdot 1)$ when compared with $O A$. However, it was significant when compared with the normal controls $(P<0 \cdot 025)$.

IgG antiglobulins were increased significantly $(\mathrm{P}<0.025)$ in RA (mean $1.62 \pm 0.16 \mathrm{mg} / \mathrm{l}$ ) compared with $\mathrm{OA}$ and were above the normal range in

Table 2 Comparison between $R A$ and $O A$

\begin{tabular}{|c|c|c|c|c|c|c|}
\hline & \multicolumn{2}{|c|}{ Immune complex } & \multicolumn{2}{|c|}{ IgG antiglobulin } & \multicolumn{2}{|c|}{ IgM antiglobulin } \\
\hline & & $\begin{array}{l}\% \\
\text { posi }\end{array}$ & & $\begin{array}{l}\% \\
\text { posi }\end{array}$ & & $\begin{array}{l}\% \\
\text { positive }\end{array}$ \\
\hline $\begin{array}{l}\text { RA synovial fluid } \\
\text { RA serum } \\
\text { OA synovial fluid } \\
\text { OA serum } \\
\text { Lab staff serum }\end{array}$ & $\begin{array}{l}3.60 \pm 0.64^{*} \\
1.48 \pm 0.18 \\
0.33 \pm 0.13 \\
0.74 \pm 0.14 \\
0.83 \pm 0.06\end{array}$ & $\begin{array}{r}88 \\
61 \\
0 \\
0 \\
0\end{array}$ & $\begin{array}{l}2 \cdot 11 \pm 0 \cdot 18 \\
1 \cdot 47 \pm 0 \cdot 19 \\
1 \cdot 00 \pm 0.13 \\
0 \cdot 73 \pm 0.03 \\
0.76 \pm 0.06\end{array}$ & $\begin{array}{r}94 \\
69 \\
25 \\
33 \\
0\end{array}$ & $\begin{array}{l}1 \cdot 50 \pm 0 \cdot 15 \\
1 \cdot 32 \pm 0 \cdot 14 \\
0 \cdot 20 \pm 0 \cdot 07 \\
0 \cdot 19 \pm 0 \cdot 01 \\
0.45 \pm 0 \cdot 03\end{array}$ & $\begin{array}{r}94 \\
87 \\
0 \\
0 \\
0\end{array}$ \\
\hline
\end{tabular}

* Milligrams anti-immunoglobulin bound/1. Values given are mean \pm standard error. 

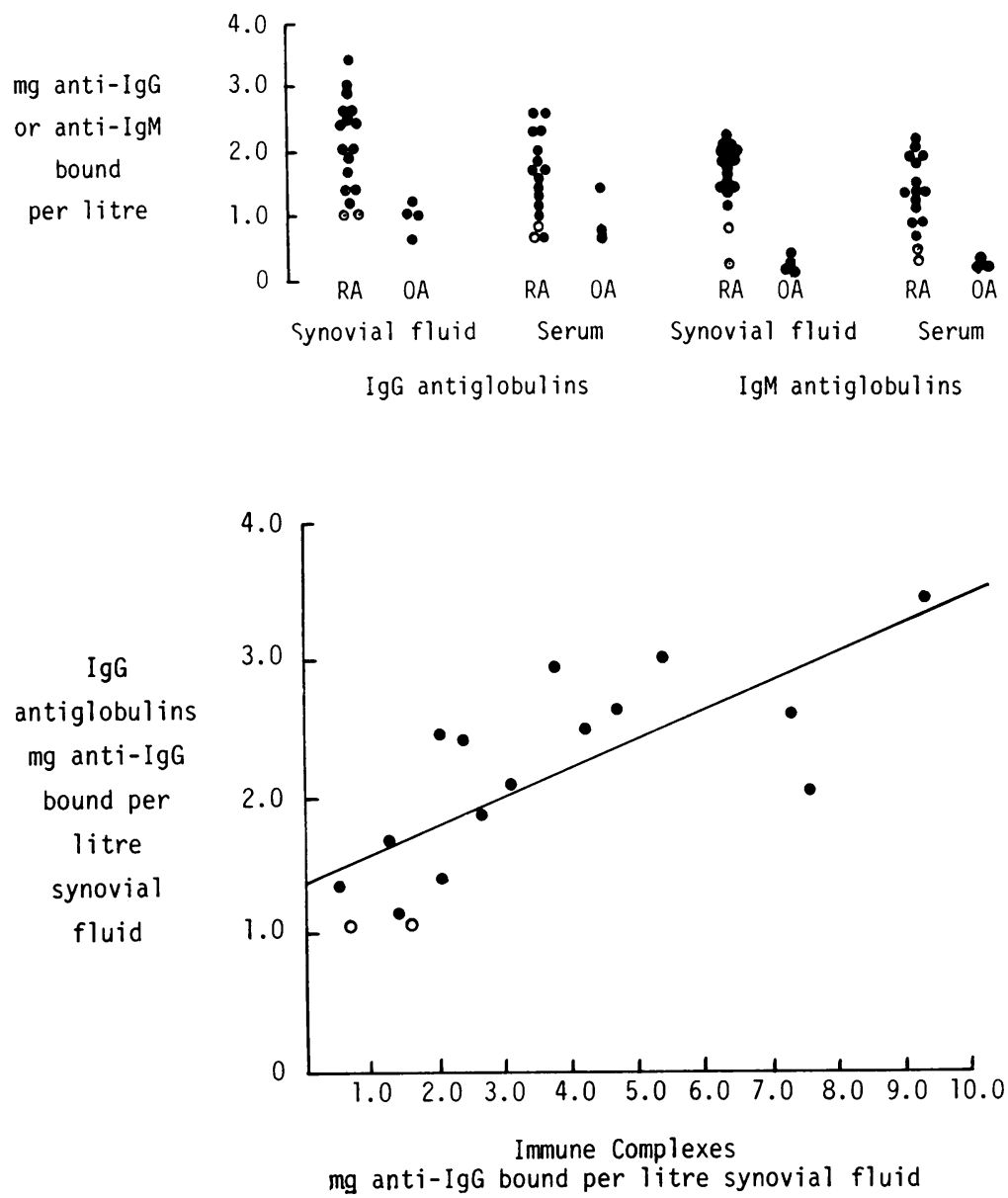

Fig. 2 IgG and IgM antiglobulins in synovial fuid and serum in $R A$ and $O A$ patients.
Fig. 3 Correlation between IgG antiglobulins and immune complexes in synovial fluid of $R A$ patients. The regression line is plotted for all the data.
11/16 patients (mean +2 SD normal controls= $1.09 \mathrm{mg} / \mathrm{l})$.

IgM antiglobulins were also significantly elevated $(P<0.005)$ in $\mathrm{RA}(1 \cdot 32 \pm 0.14 \mathrm{mg} / \mathrm{l})$ compared with OA $(0.19 \pm 0.01 \mathrm{mg} / \mathrm{l})$ and were above the normal range in $14 / 16$ patients (mean + 2SD normals = $0.58 \mathrm{mg} / \mathrm{l})$. In fact the only RA patients with normal values were the two found to be 'seronegative' by classical agglutination techniques.

The correlations between the levels of immune complex and IgG antiglobulins $(r=0.35, P<0.3$; Fig. 4) and between the 2 classes of antiglobulins $(r=0.29, P<0.3)$ were much weaker than in synovial fluid.

COMPARISON OF SYNOVIAL FLUID AND SERUM There was a correlation between immune complexes in synovial fluid and in serum $(r=0.56, P<0.05)$, although the amounts were generally much higher in synovial fluid (Fig. 5). A stronger correlation existed for IgG antiglobulins $(\mathrm{r}=0.66, \mathrm{P}<0.01)$, and the levels were comparable for paired samples of syno-국 vial fluid and serum (Fig. 6). Also there was a strong correlation between serum and synovial IgM antiglobulins $(r=0.75, P<0.001$; Fig. 7).

\section{RELATIONSHIP BETWEEN CLINICAL}

STATUS AND LEVELS OF IMMUNE

COMPLEXES AND ANTIGLOBULINS

There did not appear to be any direct relationship between the synovial fluid and serum levels of immune complexes or IgG or IgM antiglobulins, and? the age or sex of the patient, the disease activity, 0 duration of disease, or drug treatment. However, levels of IgG antiglobulins were significantly higher, in the serum of RA patients with rheumatoid nodules傮 than in those without extra-articular manifestations (Table 3). 


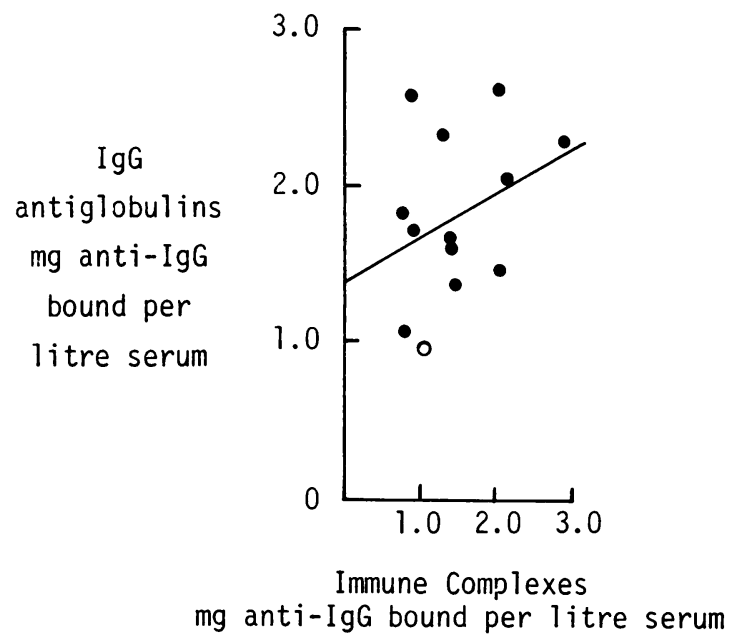

Fig. 4 Correlation between IgG antiglobulins and immune complexes in serum of $R A$ patients. The regression line for all the data is shown.

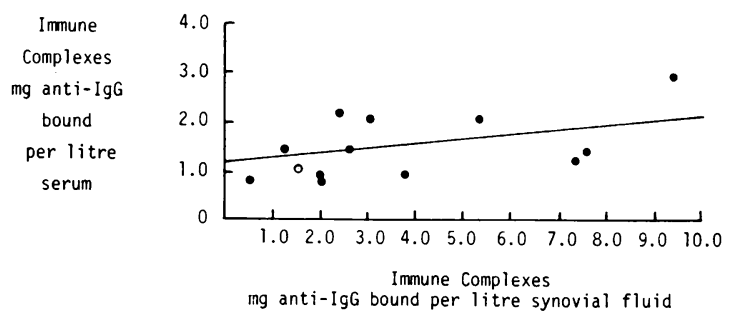

Fig. 5 Correlation between serum and synovial fluid levels of immune complexes in RA patients. The regression line for all the data is shown.

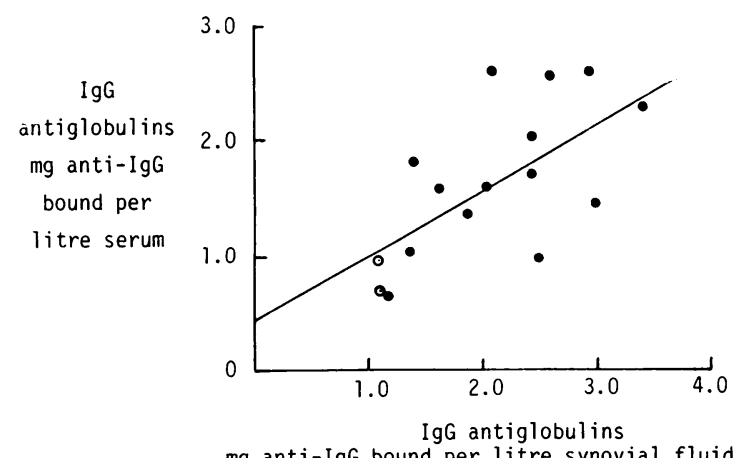

Fig. 6 Correlation between serum and synovial fluid levels of IgG antiglobulins in RA patients. The regression line for all the data is shown.

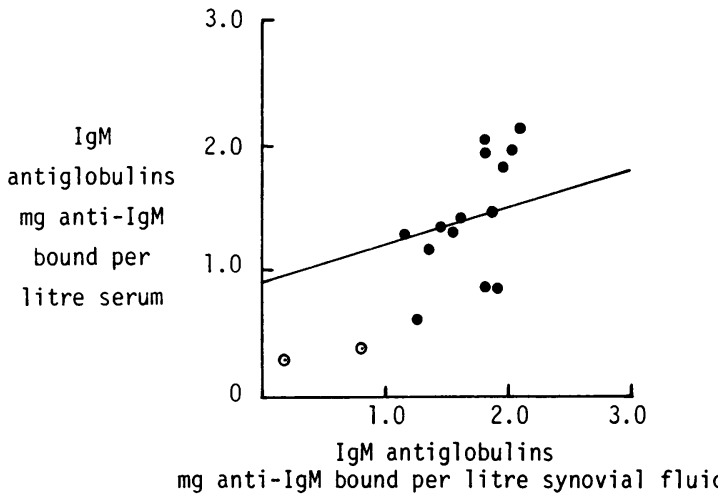

Fig. 7 Correlation between serum and synovial fluid levels of IgM antiglobulins in $R A$ patients. The regression line for all the data is shown.

Table 3 Antiglobulins and immune complexes in $R A$ patients with and without nodules

\begin{tabular}{llll}
\hline & $\begin{array}{l}\text { RA with } \\
\text { Nodules }\end{array}$ & $\begin{array}{l}\text { RA without } \\
\text { Nodules }\end{array}$ & $P$ \\
\hline Serum IgG antiglobulin & $2 \cdot 16 \pm 0.51 *$ & $1.30 \pm 0.48$ & $<0.005$ \\
$\begin{array}{l}\text { Serum IgM antiglobulin } \\
\text { Serum immune complex }\end{array}$ & $1.52 \pm 0.58$ & $1.20 \pm 0.58$ & $<0.4$ \\
$\begin{array}{c}\text { Synovial fluid IgG } \\
\text { antiglobulin }\end{array}$ & $1.60 \pm 0.80$ & $1.39 \pm 0.55$ & $<0.6$ \\
$\begin{array}{c}\text { Synovial fluid IgM } \\
\text { antiglobulin }\end{array}$ & $1.57 \pm 0.57$ & $1.85 \pm 0.69$ & $<0.05$ \\
$\begin{array}{c}\text { Synovial fluid immune } \\
\text { complex }\end{array}$ & $4.81 \pm 3.02$ & $2.94 \pm 2.29$ & $<0.2$ \\
\hline
\end{tabular}

*Mean \pm standard deviation, $\mathrm{mg} / \mathrm{l}$

\section{Discussion}

There is now good evidence that immune complexes and antiglobulins are present in both the serum and synovial fluid of patients with rheumatoid arthritis and play an important role in the pathogenesis of the synovial inflammatory response (Ziff, 1974). In the present study over $60 \%$ of patients had some increase in complexes in their sera, while nearly $90 \%$ had synovial fluid complexes. Not only did more patients have joint complexes, but the levels were markedly higher than in the serum. However, despite these differences there was a correlation between the amounts in synovial fluid and serum. Similar incidences of serum and synovial complexes have been found by Zubler et al. (1976) and Gabriel and Agnello (1977). Care must always be taken in interpreting immune complex results, as the detection rate is very dependent on the test system used. Using monoclonal rheumatoid factor Luthra et al. 
(1975) found $26 \%$ of patients had raised serum complexes and only $22 \%$ showed any increase in the synovial fluid values. Certainly most methods including the solid phase $\mathrm{Clq}$ assay used in this study, have different sensitivities depending on the size of the complex, and various tests have greater affinity for complexes in certain diseases (Lambert et al., 1977). Even within one disease such as rheumatoid arthritis complications may arise in comparing synovial with serum complexes because of possible differences in size and composition of the complexes in different sites.

In accord with earlier findings (Hay et al., 1975) both IgG and IgM antiglobulins were raised in most RA patients. Although the differences were not as striking as those found for immune complexes, the levels of IgG antiglobulins-and to a somewhat less extent IgM antiglobulins-were nearly always higher in synovial fluids than in the corresponding serum sample. This strongly points to the joint tissue as the major site of antiglobulin synthesis, with most, if not all, of the increased serum rheumatoid factor being attributable to 'spillover'. The correlation between serum and synovial fluid values would be consistent with this view. There is certainly ample evidence for local synthesis from the studies of Munthe and Natvig (1972) which showed that a major proportion of the plasma cells in the inflamed rheumatoid synovium are engaged in the synthesis of antiglobulins.

Intra-articular production of antiglobulins, in particular those of the IgG class, could account for the better correlation between IgG antiglobulins and complex levels in the joint rather than serum, and also the more marked elevation of complexes relative to antiglobulins in the synovial fluid. An IgG antiglobulin is a unique molecule in the sense that its antibody specificity is directed to a site on its own Fc fragment, thereby endowing it with the ability to self-associate (Pope et al., 1974). As shown in Fig. 8, high local concentrations in the joints would lead to the formation of large self-associated aggregates, whereas in the serum, with its much higher relative concentration of normal immunoglobulin, the equilibrium is shifted towards the formation of small complexes.

Whereas the large articular complexes would be potent activators of complement and macrophages, these small serum complexes are probably relatively harmless as evidenced by the lack of renal involvement compared with SLE. Certainly there is little evidence of serum complement activation (Winchester et al., 1971) except in the presence of systemic disease (Hunder and McDuffie, 1973). However, Nydegger et al. (1977) have found increased levels of circulating C3d, but this could

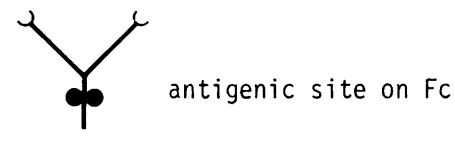

(a) IgG antiglobulin

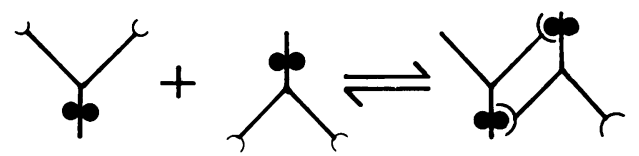

(b) Strong self-association of IgG anti-globulin througn the extra binding forces of multipoint attacinment (bonus effect of multivalency). Larger aggregates may be stabilized by IgM anti-globulins and $\mathrm{Clq}$ which are polyvalent binding agents with respect to IgG FC.
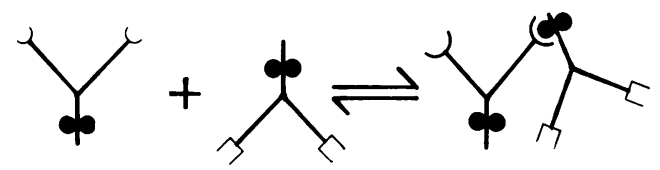

(c) Weak association between IgG anti-globulin and $\vec{\theta}$ an irrelevant IgG molecule forming a complex held by only one bond.

Fig. 8 Complex formation by $1 \mathrm{gG}$ antiglobulins. Local production in joints encourages the build up of aggregates by reaction (b). In serum, competition from irrelevant IgG will lead to complexes of smaller size and lower concentration through the dominance of reaction (c).

possibly be an overflow from inflamed joints or extra-articular disease sites.

Six of the 15 RA patients had subcutaneous nodules. There was a tendency for IgM antiglobulins and immune complex levels to be higher in this group but the presence of nodules correlated most significantly with raised IgG antiglobulins. Without excluding a role for IgM rheumatoid factors, this $\frac{7}{0}$ would be consistent with the notion that local production of IgG antiglobulins could be a major $N^{N}$ factor in the generation of these granulomatous $N$ structures (Nowoslawski and Brzosko, 1967).

We thank Miss Christine Meats for preparation of this manuscript. The work was supported in part by the Medicalc Research Council.

\section{References}

Gabriel, A., and Agnello, V. (1977). Detection of immune $\overparen{\mathbb{D}}$ complexes 1. The use of radioimmunoassays with $\mathrm{C} 1 \mathrm{q} \varrho$ and monoclonal rheumatoid factor. Journal of Clinical Investigation, 59, 990-1001. 
Hannestad, K. (1967). Presence of aggregated $\gamma$-globulin in certain rheumatoid synovial effusions. Clinical and Experimental Immunology, 2, 511-529.

Hay, F. C., Nineham, L. J., and Roitt, I. M. (1975). Routine assay for detection of IgG and IgM antiglobulins in seronegative and seropositive rheumatoid arthritis. British Medical Journal, 3, 203-204.

Hay, F. C., Nineham, L. J., and Roitt, I. M. (1976). Routine assay for the detection of immune complexes of known immunoglobulin class using solid phase C1q. Clinical and Experimental Immunology, 24, 396-400.

Hunder, G. G., and McDuffie, F. C. (1973). Hypocomplementemia in rheumatoid arthritis. American Journal of Medicine, 54, 461-472.

Kunkel, H. G., Müller-Eberhard, H. J., Fudenberg, H. H., and Tomasi, T. B. (1961). Gammaglobulin complexes in rheumatoid arthritis and certain other conditions. Journal of Clinical Investigation, 40, 117-129.

Lambert, P. H., Dixon, F. J., Zubler, R. H., Agnello, V., Cambiaso, C., Casali, P., Clarke, J., Cowdery, J. S., McDuffie, F. C., Hay, F. C., MacLennan, I. C. M., Masson, P., Müller-Eberhard, H. J., Penttinen, K., Smith, M., Tappeiner, G., Theofilopoulos, A. N., and Verroust, P. (1978). A WHO collaborative study for the evaluation of eighteen methods for detecting immune complexes in serum. Journal of Laboratory and Clinical Immunology, 1, $1-15$.

Luthra, H. S., McDuffie, F. C., Hunder, G. G., and Samayoa, E. A. (1975). Immune complexes in sera and synovial fluids of patients with rheumatoid arthritis. Radioimmunoassay with monoclonal rheumatoid factor. Journal of Clinical Investigation, 56, 458-466.

Munthe, E., and Natvig, J. B. (1972). Immunoglobulin classes, subclasses and complexes of IgG rheumatoid plasma cells. Clinical and Experimental Immunology, 12, 55-70.

Nineham, L. J., Hay, F. C., and Roitt, I. M. (1976). Laboratory diagnosis of rheumatoid arthritis: a solid phase radioassay for IgG and IgM antiglobulins. Journal of Clinical Pathology, 29, 1121-1126.

Nowoslawski, A., and Brzosko, W. J. (1967). Immunopathology of rheumatoid arthritis. II. The rheumatoid nodule (The rheumatoid granuloma). Pathologia Europaea, 2, 302-321.

Nydegger, U. E., Zubler, R. H., Gabay, R., Joliat, G., Karagevrekis, C. H., Lambert, P. H., and Miescher, P. A. (1977). Circulating complement breakdown products in patients with rheumatoid arthritis. Correlation between plasma C3d, circulating immune complexes, and clinical activity. Journal of Clinical Investigation, 59, 862-868.

Pope, R. M., Teller, D. C., and Mannik, M. (1974). The molecular basis of self-association of antibodies to IgG (rheumatoid factors) in rheumatoid arthritis. Proceedings of the National Academy of Sciences, 71, 517-521.

Torrigiani, G., Roitt, I. M., Lloyd, K. N., and Corbett, M. (1970). Elevated IgG antiglobulins in patients with seronegative rheumatoid arthritis. Lancet, 1, 14-16.

Winchester, R. J., Agnello, V., and Kunkel, H. G. (1970). Gammaglobulin complexes in synovial fluids of patients with rheumatoid arthritis: partial characterization and relationship to lowered complement levels. Clinical and Experimental Immunology, 6, 689-706.

Winchester, R. J., Kunkel, H. G., and Agnello, V. (1971) Occurrence of $\gamma$-globulin complexes in serum and joint fluid in rheumatoid arthritis patients: use of monoclonal rheumatoid factors as reagents for their demonstration. Journal of Experimental Medicine, 134, 286s-295s.

Ziff, M. (1974). Autoimmune processes in rheumatoid arthritis. Progress in Immunology II, 5, 37-46.

Zubler, R. H., Nydegger, U., Perrin, L. H., Fehr, K., McCormick, J., Lambert, P. H., and Miescher, P. A. (1976). Circulating and intra articular immune complexes in patients with rheumatoid arthritis. Correlation of ${ }^{125} \mathbf{I}$ Clq binding activity with clinical and biological features of the disease. Journal of Clinical Investigation, 57, 13081319. 